\title{
Predicting the onset and persistence of episodes of depression in primary health care. The predictD-Spain study: Methodology
} Juan Ángel Bellón*1, Berta Moreno-Küstner ${ }^{2}$, Francisco Torres-González ${ }^{3}$, Carmen Montón-Franco ${ }^{4}$, María Josefa GildeGómez-Barragán ${ }^{5}$, Marta Sánchez-Celaya ${ }^{6}$, Miguel Ángel Díaz-Barreiros7 ${ }^{7}$ Catalina Vicens ${ }^{8}$, Juan de Dios Luna9 ${ }^{9}$ Jorge A Cervilla³, Blanca Gutierrez ${ }^{3}$, María Teresa Martínez-Cañavate ${ }^{10}$, Bárbara Oliván-Blázquez ${ }^{11}$, Ana VázquezMedrano5 ${ }^{5}$ María Soledad Sánchez-Artiaga12, Sebastia March13, Emma Motrico2 ${ }^{2}$ Victor Manuel Ruiz-García², Paulette Renée BrangierWainberg ${ }^{14}$, María del Mar Muñoz-García ${ }^{3}$, Irwin Nazareth ${ }^{15}$, Michael King ${ }^{16}$ for the predictD group

\begin{abstract}
Address: ${ }^{1}$ Departamento de Medicina Preventiva, Universidad de Málaga; Unidad de Investigación de Atención Primaria de Málaga (redIAPP, grupo SAMSERAP), Centro de Salud El Palo, Spain, ${ }^{2}$ Facultad de Psicología. Universidad de Málaga; Fundación IMABIS; Distrito Sanitario Málaga. Unidad de Investigación de Atención Primaria de Málaga (redIAPP, grupo SAMSERAP), Spain, ${ }^{3}$ Departamento de Psiquiatría y Medicina legal, Universidad de Granada; Grupo Andaluz de Investigación en Salud Menta, Granada, Spain, ${ }^{4}$ Departamento de Medicina y Psiquiatría, Universidad de Zaragoza; Centro de Salud Casablanca. (redIAPP, grupo Aragón), Zaragoza, Spain, ${ }^{5}$ Servicio Riojano de la Salud; Unidad Docente de Medicina Familiar y Comunitaria de La Rioja, Logroño, La Rioja, Spain, ${ }^{6}$ Servicio Madrileño de Salud; Área I de Atención Primaria, Unidad Docente de Medicina Familiar y Comunitaria, Madrid, Spain, ${ }^{7}$ Servicio Canario de Salud, Gerencia de Atención Primaria de Gran Canaria, Centro de Salud Vecindario, Las Palmas, Spain, ${ }^{8}$ Instituto Balear de la Salud; Unidad Docente de Medicina Familiar y Comunitaria de Mallorca, Centro de Salud son Serra-La Vileta, Palma de Mallorca, Illes Balears, Spain, ' ${ }^{2}$ Departamento de Bioestadística (redIAPP, grupo SAMSERAP), Universidad de Granada, Spain, ${ }^{10}$ Unidad Docente de Medicina Familiar y Comunitaria de Granada (redIAPP, grupo SAMSERAP), Spain, ${ }^{11}$ Instituto Aragonés de Ciencias de la Salud, Unidad de Investigación de Atención Primaria (redIAPP, grupo Aragón), Zaragoza, Spain, ${ }^{12}$ Servicio Madrileño de Salud, Área 6 de Atención Primara, Centro de Salud Condes de Barcelona-Boadilla, Madrid, Spain, ${ }^{13}$ Instituto Balear de la Salud, Unidad de Investigación de Atención Primaria de Baleares (redIAPP, grupo Baleares), Mallorca, Spain, ${ }^{14}$ Servicio Andaluz de Salud, Distrito Sanitario Málaga. Unidad de Investigación de Atención Primaria de Málaga (redIAPP, grupo SAMSERAP), Spain, ${ }^{15}$ Medical Research Council General Practice Research Framework, London, UK and ${ }^{16}$ Department of Mental Health Sciences, UCL, London, UK
\end{abstract}

Email: Juan Ángel Bellón* - JABELLON@terra.es; Berta Moreno-Küstner - bertamk@uma.es; Francisco Torres-González - ftorres@ugr.es; Carmen Montón-Franco - carmenmonton@able.es; María Josefa GildeGómez-Barragán - jggomez@riojasalud.es; Marta SánchezCelaya - mscelaya@gmail.com; Miguel Ángel Díaz-Barreiros - mdiazba@comlp.es; Catalina Vicens - domcatrin@telefonica.net; Juan de Dios Luna - jdluna@ugr.es; Jorge A Cervilla - jacb@ugr.es; Blanca Gutierrez - blancag@ugr.es; María Teresa Martínez-

Cañavate - tmcanavate@samfyc.es; Bárbara Oliván-Blázquez - bolivan.iacs@aragob.es; Ana Vázquez-Medrano - avazquez@ riojasalud.es; María Soledad Sánchez-Artiaga - malus209@hotmail.com; Sebastia March - smarch@ibsalut.caib.es; Emma Motrico - emm@uma.es; Victor Manuel Ruiz-García - vmruiz@uma.es; Paulette Renée Brangier-Wainberg - paulette.brangier@gmail.es; María del Mar MuñozGarcía - marmg@ugr.es; Irwin Nazareth - i.nazareth@pcps.ucl.ac.uk; Michael King - m.king@medsch.ucl.ac.uk; the predictD group - JABELLON@terra.es

* Corresponding author

Published: 25 July 2008

BMC Public Health 2008, 8:256 doi:10.1 186/147/-2458-8-256
Received: 25 January 2008

Accepted: 25 July 2008

This article is available from: http://www.biomedcentral.com/I47I-2458/8/256

C 2008 Bellón et al; licensee BioMed Central Ltd.

This is an Open Access article distributed under the terms of the Creative Commons Attribution License (http://creativecommons.org/licenses/by/2.0), which permits unrestricted use, distribution, and reproduction in any medium, provided the original work is properly cited.

\footnotetext{
Abstract

Background: The effects of putative risk factors on the onset and/or persistence of depression remain unclear. We aim to develop comprehensive models to predict the onset and persistence of
} 
episodes of depression in primary care. Here we explain the general methodology of the predictDSpain study and evaluate the reliability of the questionnaires used.

Methods: This is a prospective cohort study. A systematic random sample of general practice attendees aged 18 to 75 has been recruited in seven Spanish provinces. Depression is being measured with the CIDI at baseline, and at 6, 12, 24 and 36 months. A set of individual, environmental, genetic, professional and organizational risk factors are to be assessed at each follow-up point. In a separate reliability study, a proportional random sample of 40 I participants completed the test-retest (25I researcher-administered and 150 self-administered) between October 2005 and February 2006. We have also checked II8,398 items for data entry from a random sample of 480 patients stratified by province.

Results: All items and questionnaires had good test-retest reliability for both methods of administration, except for the use of recreational drugs over the previous six months. Cronbach's alphas were good and their factorial analyses coherent for the three scales evaluated (social support from family and friends, dissatisfaction with paid work, and dissatisfaction with unpaid work). There were 191 (0.16\%) data entry errors.

Conclusion: The items and questionnaires were reliable and data quality control was excellent. When we eventually obtain our risk index for the onset and persistence of depression, we will be able to determine the individual risk of each patient evaluated in primary health care.

\section{Background}

\section{Depression as a public health problem}

In 2001 depression was the third leading cause of disease burden in high-income countries [1]. In 2004 the total annual cost of depression in Europe was estimated to be 118 billion euros, or 253 euros per inhabitant [2]. The prevalence of major depression is about $7 \%$ in the community [3] and 14\% in general practice attendees [4]. Relapse is frequent up to 10 years after the first presentation [5] and residual disability is common [6].

\section{Risk factors for depression}

The prevalence of depression is determined by exposure to risk factors that precipitate or maintain episodes of depression. With few exceptions, the prevalence and incidence of depressive disorders are higher in females than males, beginning at mid-puberty and persisting through adult life, although the determinants of gender differences are far from being established [7]. Socio-economic risk factors that might conceivably be addressed include low income and financial strain [8], unemployment [9], work stress [10], social isolation [11] and poor housing [12]. Relative poverty and unemployment are associated with a longer duration of episodes of depression rather than their onset [8], and depressive symptoms are also associated with subsequent unemployment and loss of family income [13]. Fixed factors such as a family history of depression [14] and personality [15] play a part but it is uncertain whether they act independently of other risk factors [16]. Physical health has been related to the onset and persistence of depression [17]. Stressful life events pose a greater risk for depression among women compared to men [18] and, like social support [19], these events also seem to be both a cause and a consequence of depression [20]. Many other candidate risk factors for depression exist, including for example childhood social disadvantage [21], childhood maltreatment [22], cigarette smoking [23], alcohol and drug abuse [24], and anxiety disorders [25].

However, the study of risk factors for depression suffers from limitations: First, it is often difficult to distinguish between their effects on the onset and on the course of depression; second, several risk factors may interact and be either a cause or a consequence of depression; and finally, few studies have controlled for candidate risk factors with comprehensive models, possibly due to the many possible factors involved.

\section{Depression risk indexes}

Effective strategies for preventing depression and reducing disease burden are hindered by a dearth of evidence about whether the risk for major depression can be quantified in the same way as other clinical disorders, such as cardiovascular diseases [26].

The predictD study is a pioneering international study whose main objective was to develop a risk index for the onset of episodes of major depression in general practice attendees [26]. The predictD international study recruited and followed-up a large sample of general practice attendees over one year. From 39 potential risk factors for depression, a risk index of 10 risk factors was drawn up with an excellent predictive power and good external validity [27]. 


\section{The predictD-Spain study}

Drawing on our experience as part of the predictD international study [28], the predictD-Spain study aimed to improve certain methodological aspects, extending the follow-up for three years, considering genetic factors in the equation (the predictD-Gene study), and studying professional and organizational factors as contributors to both the onset and persistence of episodes of depression (the predictD-Services study).

A genetic predisposition to depression may be a potential risk factor in the development of depression. Although the neurobiological equivalent of the predisposition remains unclear, the brain's serotonin system appears to play an important mediating role. Individuals with the 5HTTLPR s/s genotype are more prone to develop depression [29], and this genotype may determine stress coping mechanisms and thereby increase stress vulnerability [30].

A recent systematic review identified only 17 longitudinal studies of depression in primary care, most of which involved small sample sizes or were relatively short-term [31]. The most usual risk factors for persistence of depression in primary care were severity and chronicity of the depressive episode, the presence of suicidal thoughts, poorer self-reported quality of life, lower self-reported social support, experiencing key life events, antidepressant use, lower education level and unemployment. However, whether differences exist in depression outcomes between patients whose depressive disorders are recognized and those whose disorders are unrecognised in primary health care is unclear [32].

In Spain, general practitioneers (GPs) failed to detect $30 \%$ of depressed patients [33], while only $30 \%$ of those diagnosed received appropiate treatment [34]. The suitable use of antidepressants, medication adherence, and 'case management' between mental health specialists and primary care professionals might be some of the best predictors for the recovery from depression [35]. Thus, the need to control for these factors in predictive models on the persistence of depression in primary care is clear [36].

Each anxiety disorder and panic attack appears to confer an independent risk for the onset of major depression [25] and an association between psychopharmacological treatment for generalized anxiety disorders and a lower risk of depression has been suggested [37]. However, anxiety disorders are not always adequately detected and managed by GPs [38]. Consequently, the detection and treatment of anxiety disorders might also condition the onset of depression.
Several GP factors are related with their ability to detect and manage psychosocial problems: gender, interview training, previous doctor-patient relationship or psychosocial orientation [39-42]. Concerning organizational factors, a recent meta-analysis showed that collaborative care for depression improved the outcome [43]. The most commonly used intervention features in the collaborative care were patient education and self-management, monitoring of depressive symptoms and treatment adherence, decision support for medication management, a patient registry, and mental health supervision of care managers [44]. Finally, one of the best professional-organizational factors associated with the recognition and good management of psychosocial problems in primary care is the length of interviews $[42,45]$.

Accordingly, we aim to develop comprehensive models to predict the onset and persistence of episodes of depression in primary care. As well as individual, genetic, and environtmental risk factors, we are also considering other professional and organizational factors. In this report we explain the general methodology of the study and evaluate the reliability of the questionnaires used.

\section{Methods/Design \\ Design}

This prospective cohort study has recruited a systematic random sample of general practice attendees to be followed up after 6, 12, 24 and 36 months. The prevalence of depression and risk factors for depression are to be assessed at baseline and at each follow-up point. After excluding the patients with depression at baseline, the incidence of depression is to be measured at $6,12,24$ and 36 months. This project is in compliance with the Helsinki Declaration and the relevant ethics committees in each province have approved the study. In representation of them, from the coordinator centre, the "Comité de Ética e Investigación Sanitaria del Distrito Sanitario de Atención Primaria de Málaga" approved the study.

\section{Setting}

Seven provinces are participating with 41 health centres and 231 GPs distributed throughout Spain: Malaga and Granada in southern Spain; Zaragoza and La Rioja in northern Spain; Madrid, capital of Spain, situated in the centre; Las Palmas in the Canary Islands; and Majorca in the Balearic Islands. Each health centre, which covers a population of 15,000 to 30,000 inhabitants from a geographically defined area, is staffed by GPs, who see patients over the age of 14 years, and by primary care paediatricians. The GPs in each health centre work as a group, with extensive primary care teams. The Spanish National Health Service provides free medical cover to $100 \%$ of the population. The health centres taking part extend over urban and rural settings in each province. 


\section{Sample and exclusion criteria}

A systematic random sample taken at regular intervals of between 4 and 6 attendees, aged 18 to 75, has been recruited in six Spanish provinces. The $7^{\text {th }}$ province, Malaga, started between October 2003 and February 2004 because it was already participating in the predictD international study [26]. The GPs introduce the study to the selected patients and request permission before contacting the assistant researcher. Patients over 75 years of age have been excluded because the prevalence of cognitive impairment increases after that age. Other exclusion criteria include inability to speak or understand Spanish (foreigners), severe organic mental disease and terminal illness, patients due to be away for more than 3 months during the coming year, and persons (representatives) who attend the surgery on behalf of the person who has the appointment (for example, to collect a prescription or a certificate). Participants who have given informed consent have an interview at the health centre within two weeks. The sample size was computed, using Obuchowski expression [46], to estimate the area under the ROC curve of the index to be obtained. Assuming an area under the ROC curve of 0.80 and a precision of 0.06 , and considering an intraclass correlation coefficient of 0.05 with an average of 11 patients per GP in the cluster, the sample size needed was 3,474 patients for an incidence of major depression of about $12 \%$ per year.

\section{Outcome measures}

Our outcome variable is a depressive disorder. Depression is measured with the 12-month (or modified to 6-month) Depression Section of the Composite International Diagnostic Interview (CIDI) [47-49], which provides psychiatric diagnoses according to ICD10 and DSM-IV.

\section{Risk factors for depression}

The selection of risk factors for the onset and persistence of depression was designed to cover all important areas identified in a systematic review of the literature, considering specially those assessed in the predictD international study [26], in addition to other possible professional and organizational risk factors. Where possible, we used published measures with established reliability and international validity, including in Spain. Where this was not possible we translated the measures into Spanish. Each translation was back-translated by professional translators. In some cases, questions were developed for the study or adapted from available standardised instruments. These questions were evaluated for test-retest reliability. Scales without validation data in Spain were also evaluated on their internal consistency and factorial validity.
Individual and environmental risk factors

- Socio-demographic factors: age, marital status, occupation, employment status, ethnicity, nationality, country of birth, educational level, income, owner occupier accommodation, living alone or with others.

- Controls, demands and rewards for unpaid and paid work, using an adapted version of the job content instrument [50].

- Debt and financial strain [9].

- Consultation rate in the general practice through computerized clinical notes [51].

- Physical and mental well-being, assessed by the SF-12 that has application across a number of cultures [52], including Spain [53]; and a question on the presence of long-standing illness, disability or infirmity.

- Alcohol abuse using the WHO AUDIT questionnaire [54], the Spanish validation of which slightly modified the threshold for female hazardous drinkers $[55,56]$.

- Use of recreational drugs (at least once in the past and over the previous six months) adapted from the relevant sections of the CIDI.

- A life-time screen for depression based on the first two questions of the CIDI. People answering yes to both questions screened positive [57].

- Brief questions on cigarette consumption.

- For women, questions on menstruation, pregnancy and childbirth from the Patient Health Questionnaire (PHQ) [58].

- Brief questions on the quality of sexual and emotional relationships with a partner, adapted from a standardized questionnaire [59].

- Presence of serious physical, psychological or substance misuse problems, or any serious disability, in persons who are close friends or relations of participants; and difficulty getting on with people and maintaining close relationships, assessed using questions from a social functioning scale [60].

- Childhood experiences of physical, emotional or sexual abuse [61].

- Nature and strength of spiritual beliefs [62]. 
- Family psychiatric history in first-degree family members requiring pharmacological or psychological treatment in primary or secondary care, and suicide in firstdegree relatives [63].

- Anxiety symptoms using the anxiety section of the PRIME-MD [58]. The Spanish version provides psychiatric diagnoses according to DSM-IV: Panic Attack, Generalised Anxiety Disorder and Other Anxiety Disorders [64].

- One question on whether and when (at what age) the participant had lost one or both parents by death.

- Household type and composition.

- The living environment, including satisfaction with neighbourhood and perception of safety inside/outside the home using questions from the Health Surveys for England [65].

- Recent life-threatening events, using a brief validated checklist [66].

- Experience of discrimination on the grounds of sex, age, ethnicity, appearance, disability or sexual orientation using questions from a recent European study [67].

- Adequacy, availability and sources of social support from family and friends [68].

\section{Genetic risk factors}

The participants give their general informed consent and are asked for a new and specific informed consent on genetic tests. We collect saliva and/or blood for genetic testing, with DNA from both blood and saliva obtained by standard procedures. The 5-HTTLPR polymorphism at SLC6A4 is to be genotyped in all samples, as described $[29,30]$.

\section{Professional and organizational risk factors}

This group of variables will be gathered from computerised clinical notes, centralised administrative records, and a brief questionnaire to the GPs at 12, 24 and 36 months.

- GP characteristics: age, gender, year of degree in Medicine, postgraduate training and speciality, type of contract, time in the current health centre, list size, mean time per patient during the previous year, satisfaction with relationships and collaborative care between GP and mental health team, social worker, and nurse practitioner, selfperceived comfort with antidepressant use, and a questionnaire on professional satisfaction, perception of workload, and psychosocial orientation [69].
- Health Centre characteristics: size of population attended, number of inhabitants in the city or town, predominant activity in the city or town (agriculture-fishing, industry or services), number and type of professionals in the team, professional-population ratios, type and intensity of relationship with Mental Health team (case management, patient care and shared continued medical education), and "centred variables" (mean or median of the GP characteristics in each health centre).

- Interaction professional-organization-patient variables: number of visits to health centre team, i.e., GP, nurse, and social worker; referrals to the Mental Health team by GPs or direct approaches to mental health specialists by the patient privately; patient's psychosocial and physical problems detected by their GPs; and antidepressants, benzodiazepines or other psychological drugs prescribed (type, dose and duration).

\section{Data checking}

Locally, each interview is checked for completion by the interviewer. Quality assurance is focused on the standardised training of researchers in the use of the CIDI and other questionnaires, on the recruitment and interviewing of patients and on data management. Over and above team meetings at the provincial level, a research coordinator assesses each interviewer twice during recruitment to monitor the interview process, verifies adherence to the CIDI and manages other problems as they arise. Progress reports for each province are submitted every two months and examined critically by the steering group at project management meetings. Each participating province double-enters $10 \%$ of its data records and a $1 \%$ error rate is accepted.

\section{Statistical analysis}

When all follow-ups are complete we shall be able to identify risk factors for the incidence (from participants not depressed at baseline) and recovery-persistence (from depressed participants) of depression over 6, 12, 24 and 36 months. The occurrence of major depression (yes/no) will be the dependent variable of multiple logistic regressions from a multilevel analysis that will discern three levels: patient, GP and health centre. The province will be included as a fixed factor since only seven units are involved. When we consider repeated measurements from different times of the follow-up, multilevel analysis will include four levels: time, patient, GP and health centre. A hierarchical model will be used to take into account the distribution of the data at different levels to estimate two types of variability, one due to individuals in the study and another due to the groups in which patients are nested. The candidate risk factors in each level will be included in the model using an entrance value of $P<0.10$. For each level, the usefulness of including first-degree 
interactions in the equation will be considered, and the interactions between levels will also be studied.

Missing data for candidate risk factors will be imputed using multiple imputation by chained equations (MICE), in which each variable is imputed using a regression model conditional on all the others, iteratively cycling through all the variables that contain missing data [70]. We will conduct the analysis in each of 10 imputed datasets and will obtain combined estimates; 10 imputed data sets is a common choice by convention [71]. We will repeat the analysis in just those participants with complete information as a sensitivity analysis. These analyses will be performed by the STATA "ice" command [72].

We will calculate the c-index [73] to estimate the discriminative power of the final model at each time. We will use a calculation proposed by Copas [74] to adjust for overfitting of our prediction models. We will assess the goodness of fit of the final risk model by grouping individuals into deciles of risk and comparing the observed probability of major depression within these groups with the average risk. We will calculate effect sizes using Hedge's g [75] for the difference in log odds of predicted probability between patients who will later be observed to be depressed and those who will not be depressed. All these analyses will be run with STATA release 10 .

We have calculated test-retest agreement using the Kappa statistic, which adjusts for chance agreement, for questions with two response options and the Intraclass Correlation Coefficient (ICC) for items with more than two [76]. We have evaluated the internal consistency of the scales through Cronbach's alpha, and explored their subjacent factors through factorial analysis by principal components and varimax rotation. Reliability and validity analyses have been run with SPSS 14 .

\section{Results \\ Reliability}

For the test-retest analysis, we selected a random sample of 401 patients stratified by province; 251 completed the predictD-Spain questionnaires as researcher-administered and 150 as self-administered questionnaires between October 2005 and February 2006. The respective distribution by province was: Madrid 41/39, Granada 40/38, La Rioja 49/24, Las Palmas 42/20, Malaga 41/0, Majorca 28/ 19 , and Zaragoza 10/10. The mean number of days between test and retest was 11.0 (95\% CI, 10.2-11.8; standard deviation $=7.5$ ).

Additional file 1 shows reliability coefficients for all items and questionnaires evaluated. Most of the coefficients were good or excellent. Use of recreational drugs over the previous six months had poor agreement for the two methods of questionnaire administration. One item on the perception of safety inside the home had a coefficient of 0.80 (excellent) for researcher-administered and 0.37 (poor) for self-administered questionnaires, and another on cigarette consumption also had poor agreement (researcher-administered $=0.85$ and self-administered $=$ 0.40 ), although only for the self-administered way.

We evaluated the internal consistency of three scales: dissatisfaction with unpaid work, dissatisfaction with paid work and social support from family and friends. The respective Cronbach's alphas were good (Additional file $1)$.

\section{Validity}

Factorial analysis of the scale dealing with social support from family and friends found one factor that explained $58.7 \%$ of the variance. Factorial analysis of the scale dealing with dissatisfaction with paid work found three factors that explained $81.6 \%$ of the variance: F1 "feeling in control" (3 items $=28.3 \%$ ), F2 "experiencing difficulty without support" (2 items $=26.4 \%)$, and F3 "experiencing distress without being respected" ( 2 items $=26.9 \%$ ). Factorial analysis of the scale dealing with dissatisfaction with unpaid work differed slightly from the scale dealing with paid work. It found two factors that explained $77.3 \%$ of the variance: F1 "feeling in control without difficulties and with gratitude" ( 5 items $=50.4 \%$ ) and F2 "experiencing distress without support and being respected" (2 items $=26.9 \%$ ).

\section{Error rates for data entry}

The baseline error rates for data entry in each province are well below the $1 \%$ level of acceptability. We have checked 118,398 items from a random sample of 480 patients stratified by province and found only 191 errors $(0.16 \%)$.

\section{Discussion}

The questionnaires used showed good reliability and the factorial validity of the three scales tested was coherent. Quality control of data was excellent.

\section{Reliability and validity analysis}

The results of reliability analyses were good or excellent for practically all the questionnaires and items. This suggests that data stability over time is satisfactory. We were interested in testing the questionnaires using both methods of administration, researcher-administered and selfadministered, since, for cultural reasons; questionnaires administered to primary care attendees in Spain are almost always researcher-administered. Moreover, we also wanted to test whether self-administered questionnaires have different degrees of reliability as a result of a different socio-cultural patient profile (higher level of education, income and social class), the variability introduced by 
interviewers, or other circumstances. In the end, the testretest reliability was similar for most items with both methods of administration, although we did not measure inter-interviewer reliability. Nevertheless, several differences were interesting. The perception of safety inside the home had an excellent coefficient for researcher-administered questionnaires and a poor coefficient for self-administered questionnaires. Perhaps not all the patients interpreted this question the same way or maybe some were less sincere. We think that it was probably a "hot" question, perhaps interpreted as domestic violence, and, when the interviewers were not directly present; the patient may have felt less need to be sincere. It might also be that the question was a bit ambiguous. Fewer doubts concerned the absence of reliability for the item on the use of any recreational drugs over the previous 6 months. It contrasted with the good reliability of the same question in reference to the use of recreational drugs at least once. From the viewpoint of social desirability it is coherent, as it is considered better to try a drug than to consume it more often. A similar reasoning could be attributed to the item on cigarette consumption per day, although it is only a hypothesis. However, the predictD-International study obtained good coefficients for both time references on drug consumption [26]. In any case, we have decided not to include the use of recreational drugs over the previous six months in the final analysis of risk factors. The items on perception of safety inside the home and consumption of cigarettes per day will also be excluded from the final analyses.

Factorial analysis and Cronbach's alpha of the scale dealing with support from family and friends showed that its use as a single scale is appropriate. This is a conceptual difference with those questionnaires that separate support from family and support from friends [77]. The 7 items that we used on dissatisfaction with paid and dissatisfaction with unpaid work were adapted from the "Job Content Questionnaire" (JCQ), based on Karasek's demandcontrol-support model [78]. Our factorial analysis of paid work identified three factors that coincide with those obtained by the JCQ in different countries (job control, social support and psychological demands). However, factorial analysis of unpaid work changed. This was to be expected, as most unpaid work was probably related with looking after the family or the home, though we are unaware of any background to this question in the literature. Whatever the case, both Cronbach's alphas justified the use of each scale as a single scale.

\section{Significance and practical implications of the study}

These comprehensive models for the prediction of depression will facilitate the understanding of its causes, specifying the contribution of each risk factor and the importance of patient, environmental, genetic, profes- sional and organizational factors. When we eventually obtain our risk index for the onset of depression, we will be able to determine the individual risk of each patient evaluated in primary health care. We hope to produce a simple prediction tool similar to the cardiovascular risk index [79]. Additionally, we plan to develop another risk index for recovery from depression, thus laying the foundation for future research on risk reduction in primary care.

\section{Abbreviations}

GPs: General Practitioners; ICD10: International Classification of Diseases, version 10; DSM-IV: Diagnostic and Statistical Manual of Mental Disorders, $4^{\text {th }}$ edition; WHO: World Health Organization; AUDIT: Alcohol Use Disorders Identification Test; PRIME-MD: Primary Care Evaluation of Mental Disorders.

\section{Competing interests}

The authors declare that they have no competing interests.

\section{Authors' contributions}

$\mathrm{JAB}$ is guarantor for the predictD-Spain study. JAB, BM-K, FT-G, and CM-F obtained funding for implementing the study in Spain. The predictD-Spain study was designed and based on an idea by $\mathrm{MK}, \mathrm{IN}$, and the predictD-Europe core group. JAB coordinated the predictD-Spain study. BM-K, FT-G, CM-F, MJGdG-B, MS-C, MAD-B, and CV coordinated the study in each Spanish province. JAC and $\mathrm{BG}$, based on the predictD-Spain and predictD-International study, designed the sub-study predictD-Gene and obtained funding for it. MTM-C, BO-B, AV-M, MSS-A, SMLL, EM-M, VMR-G, PRB-W collaborated implementing the study in each province. JDL collaborated in the design, and JDL and JAB analysed the data. JAB drafted the paper and all authors agreed the final version.

\section{Additional material}

\author{
Additional file 1 \\ Table 1. Reliability analysis by predictD - Questionnaires. \\ Click here for file \\ [http://www.biomedcentral.com/content/supplementary/1471- \\ 2458-8-256-S1.doc]
}

\section{Acknowledgements}

The research in Spain was funded by grants from the Spanish Ministry of Health (grant FIS references: PI04/I 980, PI0/4 I77I, PI04/2450, and PI06/ 1442), Andalusian Council of Health (grant references: 05/403, 06/278 and 08/0194), and the Spanish Ministry of Education and Science (grant reference SAF 2006/07/ 92). The Malaga sample, as part of the predictD-International study, was also funded by a grant from The European Commission (reference QL4-CT2002-00683). 
We thank the interviewers, general practitioners and patients who participated in this study in each province. We are also grateful to the Primary Care District of Malaga, particularly to Jose Miguel Morales and Maximiliano Villaseca for their support; and the Spanish Network of Primary Care Research "redIAPP" (RD06/0018), "Aragón group" (RD06/0018/0020), and "SAMSERAP group" (RD06/00I8/0039 and PAI/CTS 587). We thank the predictD-Europe Core group members (Miguel Xavier, Igor Svad, HeidiIngrid Maaros, Jan Neelman, Francisco Torres-González, Irwin Nazareth and Michael King) for being pioneers in the building of overall risk for the prediction of depressive episodes in primary health care.

\section{References}

I. Lopez AD, Mathers CD, Ezzati M, Jamison DT, Murray CJL: Global and regional burden of disease and risk factors, $200 \mathrm{I}$ : systematic analysis of population health data. Lancet 2006 , 367:1747-57.

2. Sobocki P, Jönsson B, Angst J, Rehnberg C: Cost of depression in Europe. J Ment Health Policy Econ 2006, 9:87-98.

3. Kessler RC, Berglund P, Denler O, Jin R, Koretz D, Merikangas KR, et al.: The epidemiology of major depressive disorder: results from the National Comorbidity Survey Replication (NCS-R) JAMA 2003, 289:3095-105

4. Aragones E, Piñol JL, Labad A, Masdeu RM, Pino M, Cervera J: Prevalence and determinants of depressive disorders in primary care practice in Spain. Int I Psychiatry Med 2004, 34:21-35.

5. Thornicroft G, Sartorius N: The course and outcome of depression in different cultures: I0-year follow-up of the WHO Collaborative Study on the Assessment of Depressive Disorders. Psychol Med 1993, 23: 1023-32.

6. Ormel J, Oldehinkel T, Brilman E, vanden Brink W: Outcome of depression and anxiety in primary care. A three-wave 3 I/2year study of psychopathology and disability. Arch Gen Psychiatry 1993, 50:759-66.

7. Piccinelli M, Wilkinson G: Gender differences in depression. $\mathrm{Br}\rfloor$ Psychiatry 2000, 177:486-92.

8. Bruce ML, Takeuchi DT, Leaf PJ: Poverty and psychiatric status. Longitudinal evidence from the New Haven Epidemiologic Catchment Area study. Arch Gen Psychiatry 199I, 48:470-4

9. Weich S, Churchill R, Lewis G, Mann A: Do socio-economic risk factors predict the incidence and maintenance of psychiatric disorder in primary care? Psychol Med 1997, 27:73-80.

10. Weich S, Lewis G: Poverty, unemployment, and common mental disorders: population based cohort study. BMJ 1998 317:115-119.

1I. Stansfeld SA, Fuhrer R, Shipley MJ, Marmot MG: Work characteristics predict psychiatric disorder: prospective results from the Whitehall II Study. Occup Environ Med 1999, 56:302-7.

12. Bruce ML, Hoff RA: Social and physical health risk factors for first-onset major depressive disorder in a community sample. Soc Psychiatry Psychiatr Epidemiol 1994, 29:165-71.

13. Weich S, Lewis G: Material standard of living, social class, and the prevalence of the common mental disorders in Great Britain. J Epidemiol Community Health 1998, 52(I):8-I4

14. Weissman MM, Wickramaratne P, Nomura $Y$, Warner V, Verdeli $H$ Pilowsky DJ, et al.: Families at high and low risk for depression: a 3-generation study. Arch Gen Psychiatry 2005, 62:29-36.

15. Kendler KS, Gatz M, Gardner CO, Pedersen NL: Personality and major depression: a Swedish longitudinal, population-based twin study. Arch Gen Psychiatry 2006, 63: I I 3-20.

16. Lewinsohn PM, Steinmetz JL, Larson DW, Franklin J: Depressionrelated cognitions: antecedent or consequence? J Abnorm Psychol 1981, 90:213-219.

17. Geerlings SW, Beekman AT, Deeg DJ, Van Tilburg W: Physical health and the onset and persistence of depression in older adults: and eight-wave prospective community-based study. Psychol Med 2000, 30:369-80.

18. Maciejewski PK, Prigerson HG, Mazure CM: Sex differences in event-related risk for major depression. Psychol Med 200I, 31:593-604

19. Leskela US, Melartin TK, Lestela-Mielonen PS, Rytsala HJ, Sokero TP, Heikkinen ME, et al.: Life events, social support, and onset of major depressive episode in Finnish patients. I Nerv Ment Dis 2004, 192:373-81.
20. Patton GC, Coffey C, Posterino M, Carlin JB, Bowes G: Life events and early onset depression: cause or consequence? Psychol Med 2003, 33:1203-10.

2I. Gilman SE, Kawachi I, Fitzmaurice GM, Buka L: Socio-economic status, family disruption and residential stability in childhood: relation to onset, recurrence and remission of major depression. Psychol Med 2003, 33:|34|-55.

22. Bernet $C Z$, Stein MB: Childhood maltreatment to the onset and course of major depression in adulthood. Depress Anxiety 1999, 9:169-74.

23. Wagena EJ, Van Amelswoort LG, Kant I, Wouters EF: Chronic bronchitis, cigarrete smoking, and the subsequent onset of depression and anxiety: results from a prospective population-based cohort study. Psychosom Med 2005, 67:656-60.

24. Hanna EZ, Grant BF: Parallels to early onset alcohol use in the relationship of early onset smoking with drug use and DSMIV drug and depressive disorders: findings from the National Longitudinal Epidemiologic Survey. Alcohol Clin Exp Res 1999, 23:513-22.

25. Goodwin RD: Anxiety disorders and the onset of depression among adults in the community. Psychol Med 2002, 32:1 | $21-4$.

26. King M, Weich S, Torres F, Svab I, Maaroos H, Neeleman J, Xavier M, Morris R, Walker C, Bellón JA, Moreno B, Rotar D, Rifel J, Aluoja A Kalda R, Geerlings MI, Carraca I, Caldas de Almeida M, Vicente B, Saldivia S, Rioseco P, Nazareth I: Prediction of depression in European general practice attendees: the PREDICT study. BMC Public Health 2006, 6(I):6.

27. King M, Carl W, Gus L, Bottomley C, Royston P, Weich S, Bellón JA, Moreno B, Švab I, Rotar D, Rifel J, Maaroos HI, Aluoja A, Kalda R, Neeleman J, Geerlings M, Xavier Miguel, Carraça I, Gonçalves-Pereira M, Vicente B, Saldivia S, Melipillan R, Torres-Gonzalez F, Nazareth I: Development and validation of an international risk prediction algorithm for episodes of major depression in general practice attendees: the predictD study. Arch Gen Psychiatry 2008 in press.

28. Bellón JA, Torres F, Moreno B, King M, Nazareth I, Xavier M, Maaros HI, Svad I, Neeleman J, Walker C, Aluoja A, Rotar D, Geerlings MI, Vicente B, Saldivia S: EI estudio PREDICT. Predicción de futuros episodios de depresión en atención primaria. Evaluación de un perfil de riesgo (PREDICT-Europe). In Estudios multicéntricos en atención primaria de Salud Edited by: Bolibar B, Cabezas C, Nin e, Violan C. Barcelona: Fundacio Jordi Gol i Gurina; 2006:219-34.

29. Cervilla JA, Rivera M, Molina E, Torres-González F, Bellón JA, Moreno B, Luna JD, Lorente JA, De Diego-Otero Y, King M, Nazareth I, Gutierrez B, PREDICT study core group: The 5-HTTLPR s/s Genotype at the Serotonin Transporter Gene (SLC6A4) Increases the Risk for depression in a Large Cohort of Primary Care Attendees: The PREDICT-Gene Study. Am J Genet Part B 2006, |4|B:912-17.

30. Cervilla J, Molina E, Rivera M, Torres-González F, Bellón JA, Moreno B, Luna JD, Lorente JA, Mayoral F, King M, Nazareth I, the PREDICT study core group, Gutierrez B: The risk for depression conferred by stressful life events is modified by variation at the serotonin transporter gene 5-HTTLPR genotype. Evidence from the Spanish PREDICT-Gene cohort. Molecular Psyquiatry 2007, I 2:748-55.

31. Gilchrist G, Gunn J: Observational studies of depression in primary care: what do we know? BMC Family practice 2007, 8:28.

32. Simon GE, Golberg D, Tiemens BG, Uscun TB: Outcomes of recognized and unrecognised depression in an international primary care study. Gen Hosp Psych 1999, 21:97-105.

33. Aragones E, Pinol JL, Labad A, Folch S, Melich N: Detection and management of depresive disorders in primary care in Spain. Int J Psychiatry Med 2004, 34:33 I-43.

34. Fernández A, Haro JM, Codony $\mathrm{H}$, Vilagut $\mathrm{G}$, Martínez-Alonso $M$, Antonell J, Salvador-Carulla L, Ayuso-Mateos JL, Fullana MA, Alonso $\mathrm{J}$ : Treatment adequacy of anxiety and depressive disorders: primary versus specialised in Spain. I Affect Disord 2006, 96:9-20.

35. Gensichen J, Beyer M, Muth C, Gerlach FM, Von Korff M, Ormel J: Case management to improve major depression in primary health care: a systematic review. Psychol Med 2006, 36:7-14.

36. Von Korff M, Goldberg D: Improving outcomes in depression. $B M]$ 200I, 323:948-9. 
37. Goodwin RD, Gorman JM: Psychopharmacologic treatment of generalized anxiety disorder and the risk of major depression. Am J Psychiatry 2002, I 59:1935-7.

38. Wittchen HU, Kessler RC, Beesdo K, Krause P, Hofler M, Hoyer J: Generalized anxiety and depression in primary care: prevalence, recognition, and management. J Clin Psychiatry 2002 63(Suppl 8):24-34

39. Lieberman JA: Medical education and patient's psychosocial needs. I Fam Pract 1999, 48:675-6.

40. Harman JS, Schulberg HC, Mulsant BH, Reynolds CF 3rd: The effect of patient and family doctor characteristics in diagnosis of depression in primary care. J Fam Pract 200I, 50:1068.

41. Hjortdahl P: The influence of GP knowledge about their patients on the clinical decision-making process. Scand J Prim Health Care 1992, 10:290-4.

42. Robinson JW, Roter DL: Counseling by primary care physicians of patients who disclose psychosocial problems. I Fam Pract 1999, 48:698-705.

43. Gilbody S, Bower P, Fetcher J, Richards D, Sutton AJ: Collaborative care for depresión: a cumulative meta-analysis and review of longer-term outcomes. Arch Intern Med 2006, I 66:23 |4-2I.

44. Williams JW, Gerrity M, Holsinger T, Dobscha S, Gaynes B, Dietrich A: Systematic review of multifaceted interventions to improve depression care. Gen Hosp Psychiatry 2007, 29:9 I-I I I.

45. Deveugele M, Derese E, Brink-Muinen A Van de, Bensing J, De Maesneer ]: Consultation length: cross sectional study in six European countries. BMJ 2002, 352:472-8.

46. Obuchowski NA: Comnpuitng sample size for receiver operating characteristic studies. Invest Radiol 1994, 29:238-43.

47. Robins LN, Wing J, Wittchen HU, Helzer JE, Babor TF, Burke J, Farmer A, Jablenski A, Pickens R, Regier DA: The Composite International Diagnostic Interview. An epidemiologic Instrument suitable for use in conjunction with different diagnostic systems and in different cultures. Arch Gen Psychiatry 1988 , 45: 1069-77.

48. World Health Organisation: Composite International Diagnostic Interview (CIDI). Version 2. I. WHO: Geneva; 1997.

49. Rubio-Stipec M, Bravo M: [The Composite International Diagnostic Interview (CIDI): an epidemiologic instrument suitable for using in conjunction with different diagnostic systems in different cultures]. Acta Psiquiat Psicol Amer Lat 1991, 37:191-204. [Article in Spanish]

50. Karasek RA, Theorell T: Healthy work: stress, productivity, and the reconstruction of working life. Basic Books: New York 1990.

5I. Dowrick CF, Bellon JA, Gomez MJ: GP frequent attendance in Liverpool and Granada: the impact of depressive symptoms. $\mathrm{Br}$ J Gen Pract 2000, 50:36I-5.

52. Jenkinson C, Layte R, Jenkinson D, Lawrence K, Petersen S, Paice C, Stradling J: A shorter form health survey: can the SF-I 2 replicate results from the SF-36 in longitudinal studies? J Public Health Med 1997, 19:179-186.

53. Gandek B, Ware JE, Aaronson NK, Apolone G, Bjorner JB, Brazier JE, Bullinger M, Kaasa S, Leplege A, Prieto L, Sullivan M: Cross-Validation of item selection and scoring for the SF- 12 Health survey in nine countries: Results from the IQOLA Project. J Clin Epidemiol 1998, I I: I I7I-8.

54. Barbor TF, de la Fuente JR, Saunders J, Grant M: The alcohol use disorders identification test: Guidelines for the use in primary health care. World Health Organisation: Geneva; 1989.

55. Rubio Valladolid G, Bermejo Vicedo J, Caballero Sánchez-Serrano MC, Santo-Domingo Carrasco J: Validation of the alcohol use disorders identification test (AUDIT) in primary care. Rev Clin Esp 1998, 198:11-4

56. Pérula-de Torres LA, Fernández-García JA, Arias-Vega R, Muriel-Palomino M, Marquez-Rebollo E, Ruiz-Moral R: Validity of AUDIT test for detection of disorders related with alcohol consumption in women. Med Clin (Barc) 2005, I 25:727-30.

57. Arroll B, Khin N, Kerse N: Screening for depression in primary care with two verbally asked questions: cross sectional study. BMJ 2003, 327: I | 44-6

58. Spitzer RL, Kroenke K, Williams JB: Validation and utility of a selfreport version of PRIME-MD: the PHQ primary care study. Primary Care Evaluation of Mental Disorders. Patient Health Questionnaire. JAMA 1999, 282: 1737-44.
59. Reynolds CF, Frank E, Thase ME, Houck PR, Jennings JR, Howell JR, Lilienfeld SO, Kupfer DJ: Assessment of sexual function in depressed, impotent, and healthy men: factor analysis of a Brief Sexual Function Questionnaire for men. Psychiatry Res 1988, 24:23I-50.

60. Tyrer P: Personality disorder and social functioning. In Measuring Human Problems: a Practical Guide Edited by: Peck DF, Shapiro CM. Wiley \& Sons, Chichester, New York; 1990: I 19-42.

6I. Fink LA, Bernstein D, Handelsman L, Foote J, Lovejoy M: Initial reliability and validity of the childhood trauma interview: a new multidimensional measure of childhood interpersonal trauma. Am J Psychiatry 1995, I 52:1329-35.

62. King M, Speck P, Thomas A: The Royal Free interview for religious and spiritual beliefs: development and standardization. Psychol Med 1995, 25: I I 25-34.

63. Qureshi N, Bethea J, Modell B, Brennan P, Papageorgiou A, Raeburn $S$, Hapgood R, Modell M: Collecting genetic information in primary care: evaluating a new family history tool. Fam Pract 2005, 22:663-9.

64. Baca E, Saiz J, Agüera L, Caballero L, Fernández-Liria A, Ramos J, Gi A, Madrigal M y Porras A: Validación de la versión española del PRIME-MD: un procedimiento para el diagnóstico de trastornos mentales en atención primaria. Actas Esp Psiquiatr 1999, 27:375-83.

65. Sproston K, Primatesta P: Health survey for England 2002: a survey carried out on behalf of the Department of Health. The health of children and young people. Volume I. The Stationery Office: London; 2003.

66. Brugha T, Bebbington P, Tennant C, Hurry J: The List of Threatening Experiences: a subset of $I 2$ life event categories with considerable long-term contextual threat. Psychol Med 1985, I5:|89-9|.

67. Janssen I, Hanssen M, Bak M, Bijl RV, de Graaf R, Vollebergh W, McKenzie $K$, van Os ]: Discrimination and delusional ideation. Br J Psychiatry 2003, I 82:71-6.

68. Blaxter M: Health and Lifestyles. Routledge, London; 1990.

69. Mira J], Llinás G, Gil V, Orozco D, Palazón I, Villater J: Validación de un instrumento para identificar estilos de práctica profesional del médico de Atención Primaria. Aten Primaria 1998, 2I:|4-22.

70. Little RJA, Rubin DB: Statistical analysis with missing data. 2nd edition. Wiley, New York; 2002

7I. Schafer JL: Multiple imputation: a primer. Stat Methods Med Res 1999, 8:3-15.

72. Royston P: Multiple imputation of missing values: update of ice. Stata Journal 2005, 5:527-36.

73. Harrell FE: Regression Modelling Strategies. New York: Springer; 200I.

74. Copas JB: Regression, prediction and shrinkage. Journal of the Royal Statistical Society (Series B) 1983, 45:3 I I-54.

75. Cooper H, Hedges LV: The Handbook of Research Synthesis. New York: Russell Sage Foundation; 1994.

76. Streiner DL, Norman GR: Health measurement scales Oxford University Press: Oxford; 1989.

77. Procidano ME, Heller K: Measures of perceived social support from friends and from family: three validation studies. $\mathrm{Am}$ Community Psychol 1983, I I: I-24

78. Karasek R, Brisson C, Kawakami N, Houtman I, Bongers P, Amick B: The job content questionnaire (JCQ): an instrument for internationally comparative assessments of psychosocial job characteristics. J Occup Health Psychol 1998, 3:322-355.

79. Conroy RM, Pyorala K, Fitzgerald AP, Sans S, Menotti A, De Backer $G$, De Bacquer D, Ducimetière $P$, Jousilahti $P$, Keil U, Njølstad I, Oganov RG, Thomsen T, Tunstall-Pedoe H, Tverdal A, Wedel H, Whincup P, Wilhelmsen L, Graham IM, SCORE project group: Estimation of ten-year risk of fatal cardiovascular disease in Europe: the SCORE project. Eur Heart J 2003, 24:987- 003.

\section{Pre-publication history}

The pre-publication history for this paper can be accessed here:

http://www.biomedcentral.com/1471-2458/8/256/pre pub 